\title{
SENSORY ANALYSIS: THE ATTRIBUTES OF PACKAGING AND PHARMACEUTICAL FORMS OF NAIL STRENGTHENERS COMMERCIALIZED IN BRAZIL
}

\author{
JHORDANA DE OLIVEIRA SILVA, LILIAN DE ABREU FERREIRA*
}

Department of Pharmaceutical Sciences, Faculty of Pharmacy, Faculdade Patos de Minas College, Juscelino Kubitschek de Oliveira Avenue 1220, Patos de Minas, Minas Gerais, Brazil Email: lyabreu@hotmail.com

Received: 01 Oct 2016 Revised and Accepted: 09 May 2017

\section{ABSTRACT}

Objective: Conduct effective sensory method on three nail strengtheners with different packaging and pharmaceutical forms commercialised in Brazil.

Methods: Two affective tests, of acceptance and sorting-preference, and a purchase intention test were conducted. The attributes packing appearance, ease of application provided by the packaging and texture and spreadability of the pharmaceutical form were evaluated, using the hedonic scale of 9 points to evaluate the attributes and 5 points to assess the intention of buying. The sensory panel was composed of 32 judges, consumers or potential consumers.

Results: On the acceptance test, the pen with emulsion pharmaceutical form obtained was most preferred on the appearance of the package (7.88) and ease of application (7.72) attributes. The sample most preferred on texture and spreadability attribute was the nail polish bottle with brush containing enamel base pharmaceutical form (8.06), followed by pen bottle containing emulsion (6.75) and dropper bottle containing oil as pharmaceutical form (5.41) respectively, with statistical significance $(\mathrm{p}<0.05)$. All samples were higher with significant difference $(\mathrm{p}<0.05)$ compared with the dropper bottle containing oil on purchase intent.

Conclusion: It was demonstrated that pen bottle had the highest preference on package appearance and ease of application attributes and the enamel base pharmaceutical form had the highest preference in the texture and spreadability attribute. The nail polish bottle containing the pharmaceutical form enamel base showed the highest preference in purchase intention and sorting-preference test.

Keywords: Quantitative Analysis, Cosmetic Technology, Consumer Behavior

(C) 2017 The Authors. Published by Innovare Academic Sciences Pvt Ltd. This is an open access article under the CC BY license (http://creativecommons.org/licenses/by/4.0/) DOI: http://dx.doi.org/10.22159/ijpps.2017v9i6.15491

\section{INTRODUCTION}

The reduction in nail strength, as well as increase in nail fragility, is more common in women, coming to affect about $20 \%$ of them. Its cause is not yet known, but the exposure to chemicals, formaldehyde, repetitive trauma and fungi can weaken the nail [1-3].

The application of emollients and nail strengtheners is helpful for strengthening brittle nails, and these are the most popular cosmetic product types to solve this problem [1-3].

As a method for development or reformulation of formulations, sensory analysis is a tool that can assess the needs of consumers, using the human senses as a critical point to the evaluation. Above all, it is essential to know the target audience, what they expect and wants from the cosmetic market, before initiating the development process $[4,5]$.

The sensory analysis also allows the determination of similarities and differences between competing products, thus analyzing consumer preference to increase product improvement [4]. In recent years, it has been introduced in the cosmetic industry, as it allows to evaluate the acceptance of cosmetics through consumer preferences, and also acceptable characteristics for potential users [4-6].

It is through the packaging that the consumer has the first contact with the product and, therefore, evaluation of the packaging is also essential, and this can be applied in comparative studies between competing products and also in acceptance or preference studies for the product, or for those yet to be launched on the market [7-9].

So, the objective of this study was to evaluate the acceptance and purchase intent of nail strengtheners of three industrialised dosage forms marketed in the Brazilian city of Patos de Minas, through affective tests.

\section{MATERIALS AND METHODS}

This is a cross-sectional study, where two affective tests were carried out, being one of them a test of acceptance and sortingpreference and the other of purchase intention through a questionnaire containing questions for each of the following attributes: ease of application provided by the packaging, sensation on skin/nail given by the dosage form after application and appearance of the packaging, in addition to a question related to purchase intent. On the sorting preference test, the volunteers ordered the samples, from less preferred to more preferred.

For the affective test of acceptance, it was used a hedonic scale of 9 points ("liked very much" to "extremely disliked") as a quantitative method described by Stone and Sidel (1993) [10], and for the purchase intent analysis was used a 5-point scale with impressions ranging from "definitely buy" to "definitely would not buy".

Three coded strengthener nail samples with packaging and different dosage forms were used, being one nail polish bottle, on pharmaceutical form of enamel base coded with 513, another on pen bottle in emulsion pharmaceutical form, encoded with 278 and the third one, glass dropper bottle containing oil as a pharmaceutical form coded with 839. All were randomly presented to the participants, one at a time.

Samples were purchased from shops in the city of Patos de Minas, Minas Gerais, and the sensory panel is constituted of 32 volunteer judges, not trained, consumers or potential consumers, formed by female students and/or employees of Faculdade Patos de Minas between 18 to $50 \mathrm{y}$ old, after approval and signing of the Term of Consent.

The study was approved by the Research Ethics Committee of Centro Universitário de Patos de Minas, Minas Gerais, Brazil, with register number: 1.564.264 (CAAE: 52191115.3.0000.5549) and 
volunteers were recruited through personal contact and instructed not to use moisturizers, hand and cuticles/nail creams, soaps, nail polishes, nail bases or other occlusive cosmetic formulations on the on the area to be tested.

The selection of volunteers was made from an interview by completing a questionnaire containing questions related to allergies to enamels, lotions and nail/cuticle fortifying bases and on the frequency of their use. Judges that used nail strengtheners at least monthly and who did not have allergies, dermatitis, fungal infections and open wounds in the region of cuticles declared in the questionnaire were included in the study.

Data analysis was performed using SPSS 22 software. The data on the sensory acceptance test were submitted, first, to the Kolmogorov-Smirnov and Shapiro-Wilk tests to verify if they had a normal distribution, proceeding with the Kruskal-Wallis variance test by posts, at the significance level of $5 \%(p=0.05)$.

When the result of Kruskal-Wallis is given as significant, the analysis is possible only if at least one of the samples differs from the others, and it is not possible to analyze precisely which of the samples showed the best results [11]. Thus, the Dunn method on a significance level of $5 \%$ was applied, so that it was possible to determine which groups had different results, which were analyzed by descriptive statistical analysis: mean, median and standard deviation. Regarding the test-ordering preference, received numbers were represented in percentage indicating the order of preference, where the most preferred received score "3", the middle note received score "2" and less preferred received score "1".

\section{RESULTS AND DISCUSSION}

Regarding the nail strengtheners use, $34.4 \%$ reported the strengtheners use at less than one time per month, followed by $24.6 \%$ that use strengtheners monthly, and $24.6 \%$ using from one to two times per week. As one of the criteria for participation in the research was the use of nail strengtheners at least one time per month, it resulted in a final sample of 32 participants.

After analysing the normal data by Kolmogorov-Smirnov and Shapiro-Wilk tests, evidence of normal distribution for evaluated variables on each sample was not found and was applied the Kruskal-Wallis test and Dunn method at a significance level of 5\%.

In table 1 are shown the mean, median and standard deviation values found between the variables for the three types of samples.

\section{Attribute analysis: package appearance}

The pen bottle (sample 278) had a higher preference, followed by nail polish bottle (sample 513) and dropper bottle (sample 839). According to the results shown in table 2, it was found that this variable did not show a statistically significant difference.

Table 1: Mean, standard deviation and median of the tested variables for the three samples

\begin{tabular}{|c|c|c|c|c|c|c|c|c|c|}
\hline \multirow[t]{2}{*}{ Attribute } & \multicolumn{3}{|c|}{ Sample 839} & \multicolumn{3}{|c|}{ Sample 278} & \multicolumn{3}{|c|}{ Sample 513} \\
\hline & Mean & $\begin{array}{l}\text { Standard } \\
\text { deviation }\end{array}$ & Median & Mean & $\begin{array}{l}\text { Standard } \\
\text { deviation }\end{array}$ & Median & Mean & $\begin{array}{l}\text { Standard } \\
\text { deviation }\end{array}$ & Median \\
\hline Package appearance & 6.88 & 2.41 & 8.00 & 7.88 & 1.48 & 8.00 & 7.34 & 1.13 & 7.50 \\
\hline Ease of application & 3.97 & 2.78 & 3.00 & 7.72 & 1.22 & 8.00 & 6.84 & 1.53 & 7.00 \\
\hline $\begin{array}{l}\text { Texture and } \\
\text { spreadability }\end{array}$ & 5.41 & 2.82 & 6.00 & 6.75 & 2.14 & 7.50 & 8.06 & 0.88 & 8.00 \\
\hline Purchase intent & 2.59 & 1.52 & 2.50 & 3.81 & 1.06 & 4.00 & 4.50 & 0.51 & 4.50 \\
\hline
\end{tabular}

Table 2: Results of the kruskal-wallis and dunn comparative tests for package appearance attribute

\begin{tabular}{|c|c|c|c|c|}
\hline \multirow[t]{2}{*}{ Samples } & \multirow[t]{2}{*}{ (p) Kruskal-Wallis } & \multicolumn{3}{|c|}{ Comparisons (Dunn method) } \\
\hline & & 839 e 278 & 839 e 513 & 278 e 513 \\
\hline Package appearance & 0.0554 & $\mathrm{~ns}^{*}$ & ns* & ns* \\
\hline
\end{tabular}

*not significant

\section{Attribute analysis: ease of application}

A preferable sample was 278 (7.72), followed by the sample 513 (6.84) and sample 839 (3.97), respectively, as shown in table 1. Compared with sample 839, both 278 and 513 had a higher statistically significant preference $(p=0.05)$. However, when compared to brush packaging, the choice for the pen was not statistically significant (table 3 ).

\section{Attribute analysis: texture and spreadability}

A preferable sample on this attribute was 513, containing enamel base (8.06), followed by emulsion containing sample 278
(6.75) and oil containing sample 839 (5.41) respectively, with statistical significance $(\mathrm{p}<0.05)$. However, when comparing samples 278 and 839, there was no statistically significant difference (table 4).

\section{Attribute analysis: purchase intent}

It was noted that sample 513 showed the highest purchase intention value, followed by samples 278 and 839, respectively. Only the comparison between samples 278 and 513 showed no statistically significant difference.

Table 3: Results of the kruskal-wallis and dunn comparative tests for ease of application attribute

\begin{tabular}{lllll}
\hline Samples & (p) Kruskal-Wallis & \multicolumn{4}{l}{ Comparisons (Dunn method) } \\
\cline { 3 - 4 } & & $\mathbf{8 3 9}$ e 278 & $\mathbf{8 3 9}$ e 513 & $\mathbf{2 7 8 \text { e 513 }}$ \\
\hline Ease of application & $<0.0001$ & $<0.05$ & $<0.05$ & $\mathrm{~ns}^{*}$ \\
\hline
\end{tabular}

* not significant

Table 4: Results of the kruskal-wallis and dunn comparative tests for texture and spreadability attribute

\begin{tabular}{lllll}
\hline Samples & (p) Kruskal-Wallis & \multicolumn{1}{l}{ Comparisons (Dunn method) } & \\
\cline { 2 - 4 } & & $\mathbf{8 3 9}$ e 278 & $\mathbf{8 3 9}$ e 513 & $\mathbf{2 7 8 \text { e 513 }}$ \\
\hline Texture and spreadability & $<0.0001$ & $\mathrm{~ns}^{*}$ & $<0.05$ & $<0.05$ \\
\hline
\end{tabular}

*not significant 
Table 5: Results of the kruskal-wallis and dunn comparative tests for purchase intent attribute

\begin{tabular}{|c|c|c|c|c|}
\hline \multirow[t]{2}{*}{ Samples } & \multirow[t]{2}{*}{ (p) Kruskal-Wallis } & \multicolumn{3}{|c|}{ Comparisons (Dunn method) } \\
\hline & & 839 e 278 & 839 e 513 & 278 e 513 \\
\hline Purchase intent & $<0.0001$ & $<0.05$ & $<0.05$ & ns* \\
\hline
\end{tabular}

*not significant

\section{Sorting-preference}

On this test, were used scores ranging from 1 (least preferred) to 3 (most preferred). Sample 513 was the one that received the highest percentage of score $3(43.76 \%)$, followed by the sample $278(37.50 \%)$ and the $839(18.75 \%)$. Sample 839 was the less preferred (fig. 1).

Several studies have been carried out on the concept of packaging, because it may be the only means of communication between a product and the final consumer in the store. In a study conducted by Hassan and Khan (2009), was concluded that packaging characteristics have a positive relationship with customers preference. Similarly, Kuvykaite et al. (2009) found out that form and material have a positive effect on consumer purchase intent [12, 13]. Most nail strengtheners containing active principles for the treatment of various diseases related to nail plate sold in Brazil are found in the pharmaceutical form of oil or dispensed in bottles with droppers mainly in drugstores.

In our study, both the pharmaceutical form of oil in dropper bottle were the least preferred by the participants. Such characteristics can influence low patient compliance, due to the long treatment periods (up to 4-8 mo) required by a nail treatment.

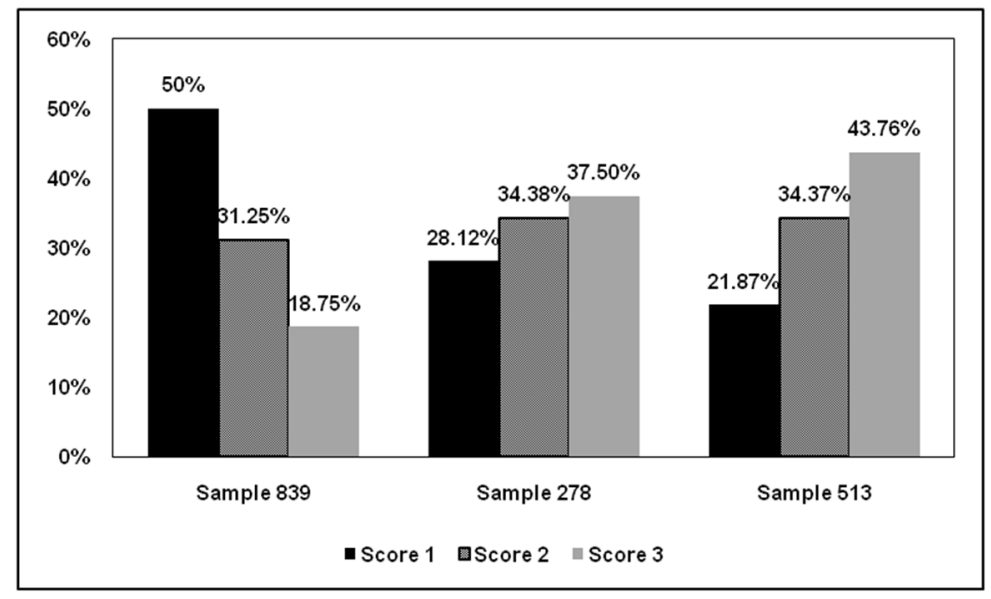

Fig. 1: Sorting-preference

The packing has gained considerable importance in the delivery of a desired quantity of product and to apply nail strengtheners containing a particular drug with ease and precision, a good brush applicator is critical, as well as a pharmaceutical form that provides longer contact time at the site of action to penetrate the nail plate in sufficient amounts to be clinically effective $[3,14,15]$. Both the pen and the nail polish bottle have brush applicator that favors the product action time, besides being preferred among the participants of the study. Therefore, it is important that all the sensory elements of the product work together to create positive perceptions about the effectiveness of the treatment that will certainly complement the therapeutic benefits.

\section{CONCLUSION}

It was demonstrated that pen bottle had the highest preference on package appearance and ease of application attributes. The enamel base pharmaceutical form had the highest preference with statistical significance in the texture and spreadability attribute. The nail polish bottle containing the pharmaceutical form enamel base showed the highest preference in purchase intention and sorting-preference test. The dropper bottle containing oil as the pharmaceutical form had lower acceptability with statistical significance on purchase intent. Under the experimental conditions of this work, an enamel base pharmaceutical form on pen package would be the nail strengthener with the best acceptance.

\section{AUTHOR CONTRIBUTION}

JOS and LAF designed the study, developed the methodology and wrote the manuscript. JOS collected the data and performed the statistical analysis. LAF supervised the study.

\section{CONFLICT OF INTERESTS}

Declared none

\section{REFERENCES}

1. Costa IMC, Nogueira LSC, Garcia PS. Síndrome das unhas frágeis. An Bras Dermatol 2007;82:263-7.

2. Holzberg M. Common nail disorders. Dermatol Clin 2006;24:349-54.

3. Patel RP, Naik SA, Patel NA, Suthar AM. Drug delivery across Human Nail. Int J Curr Pharma Res 2009;2:1-7.

4. Isaac V, Chiari BG, Magnami C, Corrêa MA. Análise sensorial como ferramenta útil no Desenvolvimento de cosméticos. Rev Cienc Farm Basica Apl 2012;33:479-88.

5. Custodio AAC. Estudos de pré-formulação e desenvolvimento de cosméticos-linha healthandbeauty; 2014. Available from: http://hdl.handle.net/11449/124269. [Last accessed on 25 Jan 2016].

6. Pensé-Lhéritier AM. Recent developments in the sensorial assessment of cosmetic products: a review. Int J Cosmet Sci 2015;37:465-73.

7. Sun C, Koppel K, Adhikari K. Sensory factors affecting female consumers' acceptability of nail polish. Int J Cosmet Sci 2015;37:642-50.

8. Wagemaker TAL, Fernandes AS, Campos PMBGM, Rodrigues LM, Rijo P. Evaluation of antioxidant and antimicrobial activities of green coffee oil in cosmetic formulations. Biomed Biopharm Res 2012;9:207-14.

9. Parente MF, Gambaro A, Solana G. Study of sensory properties of emollients used in cosmetics and their correlation with physicochemical properties. J Cosmet Sci 2005;56:175-82. 
10. Stone H, Sidell J. Sensory Evaluation Practices. New York: Academic Press; 1993.

11. Siegel S, Castellan NJJ. Estatística não paramétrica para ciências do comportamento. 2. ed. Porto Alegre: artmed; 2006.

12. Hasan SA, Khan MZ. The impact of packaging characteristics on consumer brand preference. South Asian Journal of Management Sciences 2010;3:1-10.

13. Kuvykaite R, Dovaliene A, Navickiene L. Impact of package elements on consumer's purchase decision. Economics Management 2009;14:441-7.
14. Kumar K, Sasikanth K, Sabareesh M, Dorababu, N. Formulation and evaluation of diacerein cream. Asian J Pharm Clin Res 2011;4:93-8.

15. Kiran SR, Chandrashekhar B, Vishnu P, Prasad MVV. Ungual drug delivery systems of ketoconazole nail lacquer. Int J Appl Pharm 2010;4:17-9.

\section{How to cite this article}

- Jhordana De Oliveira Silva, Lilian De Abreu Ferreira. Sensory analysis: the attributes of packaging and pharmaceutical forms of nail strengtheners commercialized in Brazil. Int J Pharm Pharm Sci 2017;9(6):176-179. 